\title{
Fast Current Control for Low Harmonic Distortion at Low Switching Frequency
}

\author{
Ashwin M. Khambadkone, Member, IEEE, and Joachim Holtz, Fellow, IEEE
}

\begin{abstract}
The structure of the current control loop of an induction machine drive determines decisively the dynamic performance of the overall system. Fast current control is a prerequisite for dynamic decoupling between the torque and the flux commands. Standard solutions are well established for drives in the low- and medium-power ranges. The low switching frequency of high-power pulsewidth modulation inverters calls for a tradeoff in controller design between the low harmonic losses and torque ripple in the steady state on one hand, and fast dynamic response during the transients on the other. The problem is developed in detail. A variable-structure approach is proposed as the solution.
\end{abstract}

Index Terms - Current control, feedback pulsewidth modulation, high-power drives, variable-structure pulsewidth modulation.

\section{INTRODUCTION}

$\mathbf{M}$ OST MODERN industrial drives use the induction motor. The method of vector control has made the control of induction motors simple and accurate. Good performance of vector control is achieved only when a fast current control is realized. In most low- and medium-power applications, fast current control methods are well established. They use mostly linear controllers in combination with space-vector modulation operated at higher switching frequency. However, problems arise in high-power applications, where, notwithstanding the advances in power device technology, the switching frequency is limited due to switching losses. Low switching frequency causes an increase in current distortion, machine losses, and torque ripple. Moreover, the use of conventional linear current controllers requires current feedback signals that are free from harmonics. Operation at low switching frequency generates harmonic error amplitudes. The distortion deteriorates the dynamics of the linear current controllers. Special measures have to be taken to extract the fundamental value of current which complicates the control scheme.

Nonlinear current controllers, in contrast, act on the instantaneous value of the current error. Hence, elaborate means, such as sampling and filtering of the current feedback signals, are not mandatory. However, nonlinear current controllers have been known to possess undesirable steady-state characteristics, such as variable switching frequency, higher current distortion,

Manuscript received November 21, 1996; revised January 17, 1998. Abstract published on the Internet July 3, 1998.

A. M. Khambadkone was with the University of Queensland, Brisbane, Australia. He is now with the Department of Electrical Engineering, Indian Institute of Science, Bangalore, 560012 India.

J. Holtz is with the Electrical Machines and Drives Laboratory, Wuppertal University, 42097 Wuppertal, Germany.

Publisher Item Identifier S 0278-0046(98)07022-1. and torque ripple. To take the advantage of the favorable properties of the nonlinear current control, this paper discusses how problems related to the steady-state characteristics can be handled and how this leads to a new current control strategy.

\section{Limitations on the Dynamic Performance of LineaR CURRENT CONTROL WITH FEEDFORWARD PWM}

The conventional method of linear current control includes a linear current controller like proportional integral (PI) or state variable type. The output of the current controller is fed to a feedforward pulsewidth modulation (PWM), for example, space-vector modulation. Moreover, the PWM can be designed to meet the desired steady-state criterion at a fixed switching frequency. At low switching frequency operation, the dynamics of the current controller are restricted due to two main reasons: firstly, the dead time introduced due to sampling and secondly, by the restriction on the gain of the controller. The current harmonics have a large amplitude at low switching frequency and they act as a noise in a linear current control loop where the fundamental value of current is controlled. Any process of extracting the fundamental value of current is associated with additional delays in the feedback loop [1]. Special sampling techniques have been proposed to extract the fundamental value of current [2], however, they are not always effective. Turn-on delays in switches, saturation of the stray inductance, and hysteresis of minor loops are some of the causes that hinder the sampling at the exact instant.

\section{STEADY-STATE Characteristics OF PULSEWIDTH MODULATORS}

The fundamental voltage vector required by the current controller is generated by the pulsewidth modulator. The performance of both these components is quantified by two typical operating conditions: steady state and the dynamic state. In steady state, the pulsewidth modulator should generate a voltage vector to satisfy given performance criteria, whereas, in the dynamic state, the voltage vector generated should rapidly reduce the current error. Steady-state characteristics of pulsewidth modulators are defined on the basis of certain performance criteria such as current distortion

$$
\left.d(m)\right|_{f_{s 1}}=\frac{I_{h}(m)}{I_{h}(m=1)}
$$

where $m$ is the modulation index, $f_{s 1}$ is the switching frequency, and $I_{h}$ is the rms value of the harmonic current, and 
torque ripple

$$
\left.\Delta T(m)\right|_{f_{s 1}}=\frac{T_{\max }-T_{\text {average }}}{T_{\text {rated }}}
$$

Although the torque ripple is related to current distortion, there is no stringent relation between the two. This implies that a reduced current distortion does not necessarily result in reduced torque ripple.

In the feedforward PWM method [3], the switching frequency is constant and, thus, the performance criteria are a function of the modulation index, or the operating point, whereas, in feedback PWM using nonlinear current control, the switching frequency varies with the operating point. The performance criteria and the switching frequency of nonlinear current control vary depending upon the choice of the current error boundary and the steady-state switching algorithm. Conventional nonlinear current controllers like the hysteresis band and its relatives seek a switching state vector to minimize the current error at the earliest. No attention is paid to the steady-state performance in these controllers. The current distortion and other criteria can be kept to a minimum by choosing a small current error boundary. This increases the switching frequency and, hence, is prohibitive in high-power applications. Here, the switching frequency must be low, and the switching algorithm must ensure a good steady-state performance. The predictive current control method adduced by Holtz and Stadtfeld [4] is a suited approach. Its performance depends on the choice of the current error boundaries in a given coordinate system. This results in different subclasses of optimal PWM methods.

\section{Minimum Switching Frequency FeEdBACK PWM WITH NONLINEAR CURRENT CONTROL}

In order to improve the steady-state performance of a feedback PWM method, an optimization criterion for the selection of the switching state vectors is introduced [4]. In such methods, possible error trajectories are predicted for the complete set of available switching state vectors of the inverter. In the event of an error limit excursion, the switching state vector which best satisfies the optimization criterion is selected as the next switching state vector. A circular error boundary is used in the case of Fig. 1. The method, widely known as the predictive current control, uses two criteria for optimization. Depending on whether the operating condition is steady state or dynamic, different criteria are applied. In the steady state, the switching frequency minimization at a given current distortion is the prime objective. Therefore, it can be called minimum switching frequency low distortion feedback $P W M$. To minimize the switching frequency, the time duration between two consecutive switching state changes is maximized. Since the change in the switching state vector occurs when the current error limit is exceeded, the selected switching state vector must maintain the current trajectory inside the error boundary for the longest possible time duration.

To obtain the optimum switching state vector, the current trajectories related to different switching state vectors are

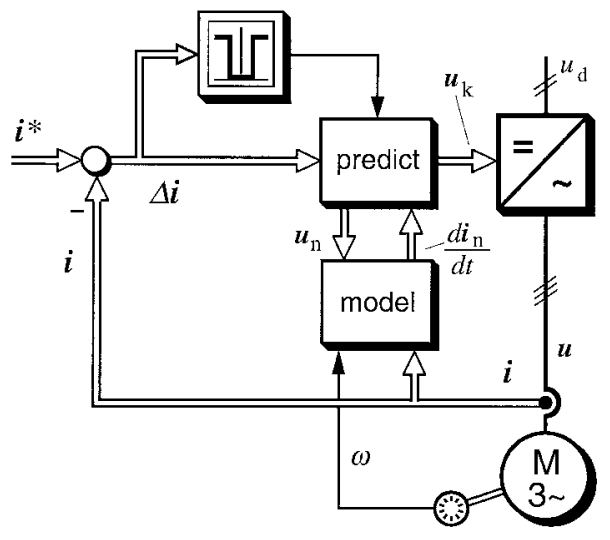

Fig. 1. Feedback PWM with optimization for circular error boundary.
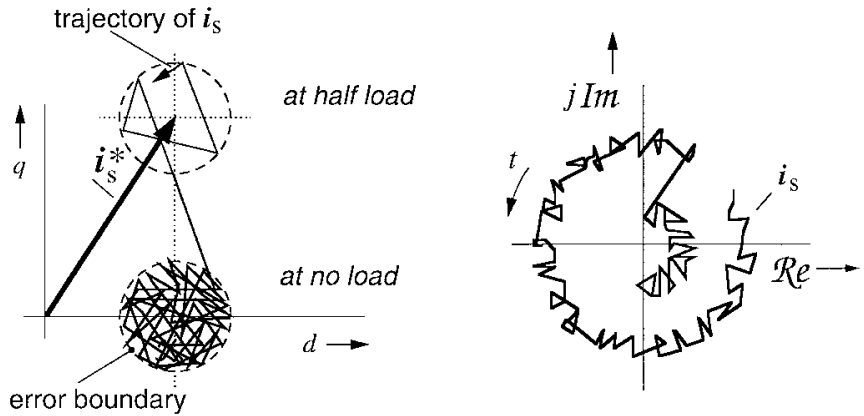

Fig. 2. Current space vector in dynamic state.

predicted using

$$
\frac{\Delta \tau(k)}{n_{c}} \longrightarrow \max
$$

where $\Delta \tau(k)$ is the duration of the $k$ th switching state and $n_{c}$ is the number of commutations required to pass to the $k$ th switching state.

Other than at steady-state condition, a fast response is required during dynamic operation. Here, the current error is large, usually greater than $25 \%$, and is caused by changes of the current reference. The criterion for selecting the switching state vector minimizes the current error as fast as possible. Such switching state vector can be determined by

$$
\frac{d e^{2}(\tau, k)}{d \tau} \longrightarrow \min
$$

where $\boldsymbol{e}=\boldsymbol{i}^{*}-\boldsymbol{i}$ is the current error vector. Note that time is normalized in this equation, $\tau=\omega \times t$.

Fig. 2 shows the current trajectory in stator coordinates and in field coordinates. It demonstrates both steady-state and dynamic operation. In order to compensate the delay time $\tau_{\text {delay }}$ caused by switching and computation, a double prediction is carried out. The predicted error $\boldsymbol{e}^{2}\left(\tau+\tau_{\text {delay }}\right)$ is obtained using a simplified linear load model.

\section{A. Minimum Switching Frequency Low Torque Ripple Feedback PWM [5]-[7]}

If the current error boundary is transformed into field coordinates, a decoupling of the current error components is 


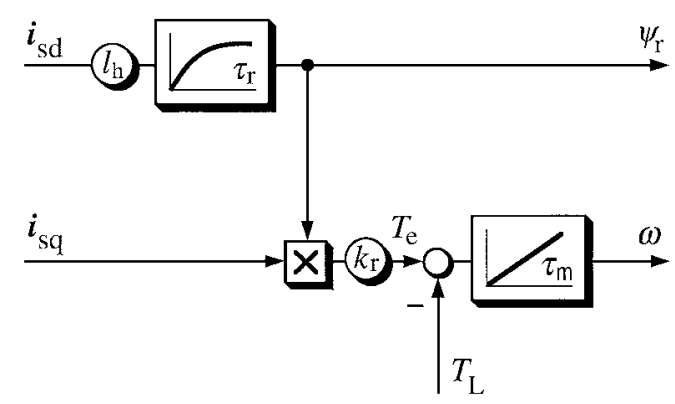

Fig. 3. Machine model in field coordinates.

possible. The advantage of such decoupling becomes clear when the current-fed machine in field coordinates is considered (Fig. 3). It can be seen that the rotor flux is produced through a large rotor time constant, hence, an appreciable amount of current harmonics can be allowed in the $d$ component of current as compared to the $q$ component.

In doing so, the torque harmonics are primarily generated by the $q$ component of current as the rotor flux remains constant. Consequently, a rectangular current error boundary in field coordinates can be defined, whereby the longer side of the rectangle is along the $d$ axis.

The switching strategies used for these error boundaries are the same as those of the predictive current control: minimum switching frequency during steady-state operation and minimum response time during dynamic operation.

The choice of rectangular error boundary in field coordinates has advantages and disadvantages. Control of the current trajectory in field coordinates entails fast current sampling and coordinate transformation. This task is eased by the availability of application-specific integrated circuits (ASIC's) that are capable of doing fast transformations. The advantage of a rectangular error boundary in field coordinates is that the choice of switching state vectors is restricted to a reduced set consisting mainly of the two active vectors neighboring the reference voltage and the two zero-switching state vectors. The remaining switching state vectors can be straightaway excluded, as described in [7]. The reduction in switching frequency achieved by a rectangular error boundary at a given value of torque ripple is shown in Fig. 4.

\section{B. Comments on Nonlinear Current Control with Minimum Switching Frequency}

The main shortcoming of the minimum switching frequency nonlinear current controller is the variation of switching frequency with the modulation index. As the switching frequency is maximum around modulation index $m=0.5$, the inverter operates at lower than possible switching frequency at modulation indices greater or less than 0.5. This leads to underutilization of the inverter switching capability. It is a property of these nonlinear current controllers that the current distortion remains fairly constant over the operating range. However, operation at a high modulation index, near $m=1$, is severely restricted when a circular error boundary is used. This is due to the particular form of the current trajectories at

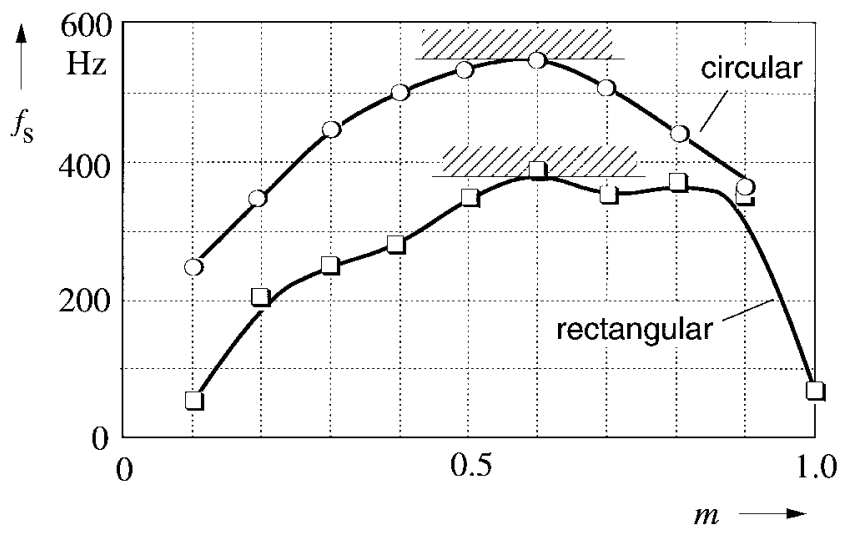

Fig. 4. Reduction in switching frequency due to rectangular error boundary.

a higher modulation index [7]. It can be remedied by using rectangular error boundary in field coordinates. In the case of a rectangular error boundary, the torque ripple can be predetermined to a fixed value, while the current distortion varies and is fairly high.

It can be concluded that the feedback PWM using a nonlinear current controller has a variable switching frequency for a given steady-state performance criterion.

\section{Nonlinear Current Control at Constant Switching Frequency}

In order to achieve constant frequency operation with nonlinear current control, a fixed-frequency clock is introduced [8]. This method introduces an average current error. Malesani et al. [9] adduced a method whereby the boundaries of the hysteresis controller are changed on-line on the basis of the predicted error. However, both these methods only satisfy the constant frequency performance common to feedforward PWM methods, whereas little is known about the other performance criteria.

Admittedly, the superior steady-state performance is a definite advantage of the feedforward PWM methods using linear current control. Moreover, the performance criteria can be influenced by an adequate choice of the switching frequency and the switching sequences, which depends on the specific modulation technique. Against this, the dynamic performance is best for the nonlinear controllers [5]-[7].

\section{VARIABle-Structure CuRRENT CONTROL}

The respective advantages of different current control methods suggest their combination in a variable-structure current control, which is presented next. In order to obtain a fast response, a large-signal algorithm is used.

\section{A. Large-Signal Algorithm}

Fig. 5 shows the switching state vectors of a two-level voltage-source inverter as represented in field coordinates. The vectors rotate at stator frequency in a direction opposite to that of the field against the stator. For a switching state vector, the rate of change of current in the $q$ direction is proportional to 
TABLE I

Switching State Vectors for Large-Signal Algorithms

\begin{tabular}{c|c|c|c|c}
\hline \multirow{2}{*}{ sector } & \multicolumn{2}{|c|}{ Positive error } & \multicolumn{2}{c}{ Negative error } \\
& $\alpha \leq 30^{\circ}$ & $\alpha>30^{\circ}$ & $\alpha \leq 30^{\circ}$ & $\alpha>30^{\circ}$ \\
\hline 0 & $S_{1}$ & $S_{2}$ & $S_{4}$ & $S_{5}$ \\
\hline 1 & $S_{2}$ & $S_{3}$ & $S_{5}$ & $S_{6}$ \\
\hline 2 & $S_{3}$ & $S_{4}$ & $S_{6}$ & $S_{1}$ \\
\hline 3 & $S_{4}$ & $S_{5}$ & $S_{1}$ & $S_{2}$ \\
\hline 4 & $S_{5}$ & $S_{6}$ & $S_{2}$ & $S_{3}$ \\
\hline 5 & $S_{6}$ & $S_{1}$ & $S_{3}$ & $S_{4}$ \\
\hline
\end{tabular}

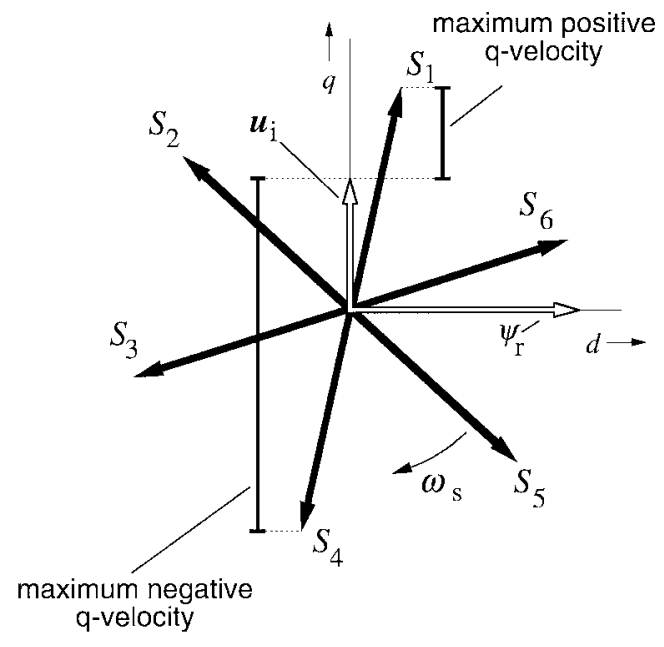

Fig. 5. Large-signal algorithm.

the $q$ component of the difference vector between the rotational EMF $u_{i}$ and the switching state vector.

A switching state vector producing a maximum rate of change of current will force the current into the required direction in the shortest possible time. If the current error is positive, that is, the current has crossed the lower $q$-error boundary, a switching state vector that forces the current in the positive $q$ direction is selected. The optimal switching state vector should produce the largest rate of change of current in the required direction. Its selection depends, therefore, on the sign of the current error, on the location of the switching state vectors with respect to the field coordinates, and on the modulation index at that instant. A simplified choice of optimal switching state vector for different angular positions can be made with reference to Table I. The angle $\alpha$ is the angle between the back EMF with respect to the switchinng state vector in any sector. In sector 0 formed by switching state vectors $S_{1}$ and $S_{2}$, (Fig. 5) $\alpha$ is the angle between $\boldsymbol{u}_{i}$ and $S_{1}$. A finer angular resolution is possible. However, there is no significant change in the value of the fastest rate of change of current beyond $30^{\circ}$. Owing to symmetry relations of the switching state vectors in a sector about the center, which has angular displacement of $30^{\circ}$ from both the active vectors, good results are obtained by using Table I.

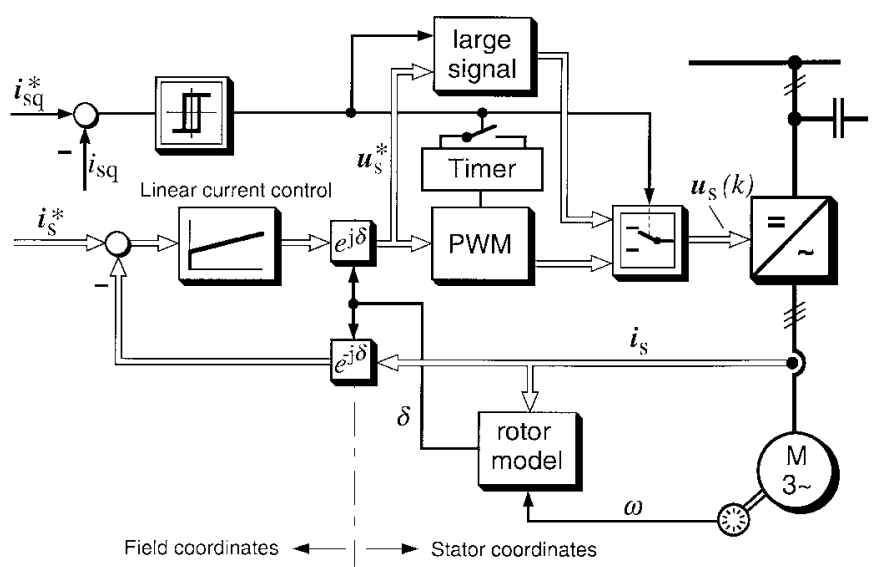

Fig. 6. Current control variable structure.

\section{B. Control Structure}

The principle idea of this variable-structure current control approach is to utilize the steady-state characteristics of the feedforward PWM and, at the same time, achieve high dynamic response of the nonlinear current control using the large-signal algorithm. A method based on the same principle was proposed in [10]. Here, the nonlinear control is carried out in stator coordinates, and there is no algorithm other than the large current error excursion to switch between the control structures. Hysteresis controllers are employed in all three phases which supersede the linear controller in each phase. This scheme may work at higher switching frequency, where the harmonic current error is inherently small. However, at the low switching frequencies in high-power applications, the harmonic current error is large and, hence, leads to indiscriminate switching between the control structures. Moreover, as hysteresis control operates individually in each phase, it can lead to a situation where the nonlinear controller is active in some phases while the linear control operates in others.

In the proposed scheme, the nonlinear controller operates in field coordinates and is activated only by a large-signal error in the $q$-current component. This has several advantages; the current error is a single complex quantity that takes into account the dynamics without causing indiscriminate operation in individual phases. In field coordinates, the $q$ component of the current is proportional to the motor torque and, thus, control of the $q$ component facilitates direct torque control. The method requires the transformation of the motor phase currents into field coordinates at a fast sampling rate. The availability of an ASIC like the ADS2100 makes this possible at a low cost.

The proposed control system is shown in Fig. 6. It consists of a vector-controlled scheme with linear current control and feedforward PWM. The nonlinear controller in field coordinates is superimposed to the linear control.

1) Hardware Implementation-Vector Control with Linear Current Control: The conventional vector control with linear current control is implemented on a Siemens microcontroller $80 \mathrm{C} 166-40 \mathrm{MHz}$. The feedforward PWM is realized as space-

\footnotetext{
${ }^{1}$ AC Vector Processor AD2S100, Analog Devices, Norwood, MA, 1993.
} 


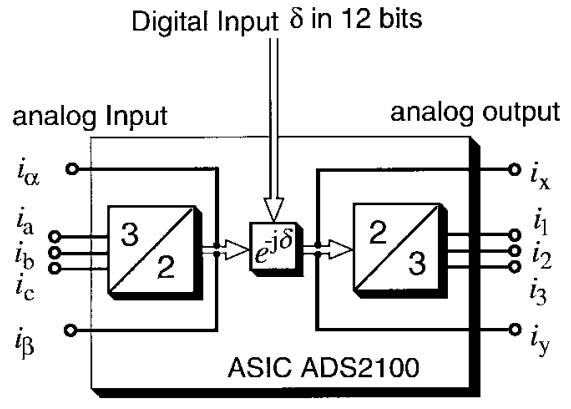

Fig. 7. ASIC-based current vector calculator.
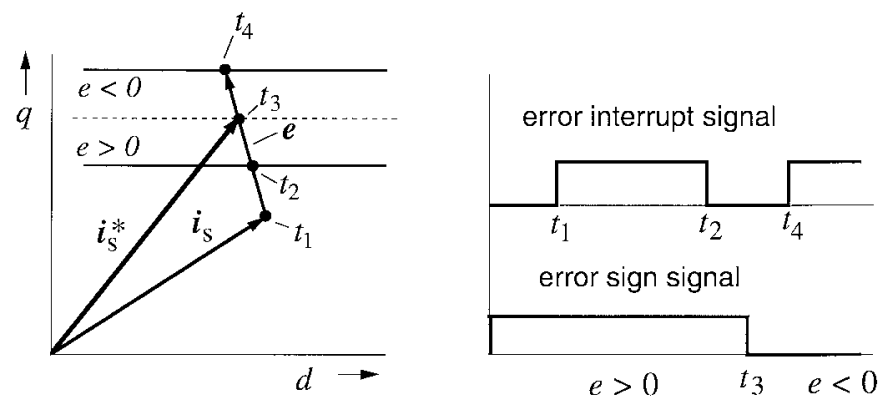

Fig. 8. Current error and sign of error.

vector modulation using the capture compare unit [11] at a switching frequency of $f_{s}=500 \mathrm{~Hz}$. A PI-type current controller is used for the prototype.

2) Nonlinear Controller: The nonlinear controller consists of a vector calculator based on the ADS2100, the structure of which is shown in Fig. 7. The cycle time of the vector transformation is $2 \mu \mathrm{s}$. The samples are updated every $20 \mu \mathrm{s}$. The current error is obtained from an analog circuit. The error calculator produces a signal for the error sign. A window comparator generates a signal at error limit excursion. The current reference $i_{s q}^{*}$ and the field angle $\delta$ are obtained from the microcontroller, while the error sign and the error limit excursion signal are connected to the capture pins of the microcontroller (Fig. 8).

\section{Control Structure Selection}

At a $q$-component current error less than the large-signal error limit, selected as $25 \%$ of rated current, the control operates in the linear current control mode (Fig. 9). As soon as the error limit is exceeded, the error limit excursion signal interrupts the processor. The interrupt signal (error limit excursion) and error sign signal are shown in Fig. 8 in a possible large-signal error scenario. In order to avoid false switching, the following condition is used:

$$
|e|>\left|e_{q \max }\right| \&\left(\frac{\left|i_{s q}^{*}[n T]\right|-\left|i_{s q}^{*}[(n-1) T]\right|}{\Delta T}>\text { rate-min }\right)
$$

which checks whether the error limit excursion has occurred as a result of a certain minimum rate of change of the $q$ component of the reference current. Thus, this condition ensures that a dynamic operation has truly occurred and the error limit excursion is not due to higher amplitude of the harmonic current. If the switching condition is satisfied, the large-signal algorithm is executed and a switching state vector from the table is put out. In doing so, the largesignal algorithm inhibits the PWM timer, thus deactivating the linear control loop. As the large-signal algorithm forces the current in the positive $q$ direction, the current error starts decreasing, as shown in Fig. 8. At time $t_{2}$, as the current error reenters the error boundary, the interrupt signal goes to zero. At $t_{3}$, the current error changes sign, and at $t_{4}$, another interrupt is produced. The change in the error sign is registered at every interrupt, thus defining each error interrupt. If the change in sign satisfies the correction condition, the largesignal algorithm is concluded. A second condition must be satisfied before switching to linear control. The condition (6) ensures that the linear current control is able to reduce the steady-state current error. The analysis of the system using the phase plane method provides such condition as

$$
e \cdot u_{s q}^{*}>0
$$

where $u_{s q}^{*}$ is taken from the output of the linear controller. Condition (6) states that $e \cdot \dot{e}<0$, thus forcing the current error trajectory in the phase plane to zero. The linear controller parameters are selected such that the above condition is satisfied. If the switching condition is satisfied, the linear current control is started anew. In order to eliminate the sampling delay during reentry to the linear control structure, the whole linear control algorithm is maintained operational during a large-signal condition. The linear current controller only tracks the current error and produces a voltage output. This output is not active as the PWM timer stands deactivated. Moreover, since the large-signal algorithm controls the error at a faster rate than the linear controller possibly could, saturation of the linear controller cannot occur. Thus, at reentry when the PWM timer is reactivated, the linear current controller is able to provide the required voltage vector.

Fig. 10 shows the operation of the variable-structure current control scheme. The large-signal operation is evidenced by the large on-time of a single switching state vector. As the current reaches the upper error limit, fast reentry into linear current control is indicated by the pulsewidth modulated output. The figure also shows the total absence of sampling delays. In comparison to that, the response of the linear current control is shown in Fig. 11. The current controller is adjusted such that stable operation is possible in the presence of large current error created by the too low switching frequency. This limits the bandwidth of the controller. The modulation index is around 0.5 . The sampling delay is also clearly visible.

Fig. 12 shows the operation of the variable-structure current control at high modulation index. Note that the steady-state current error is considerably larger than the large-signal error limit. The switching condition in (5) ensures stable operation under such condition.

\section{CONCLUSION}

At low switching frequency, there is a clear demarcation between the steady-state and the dynamic performance of 


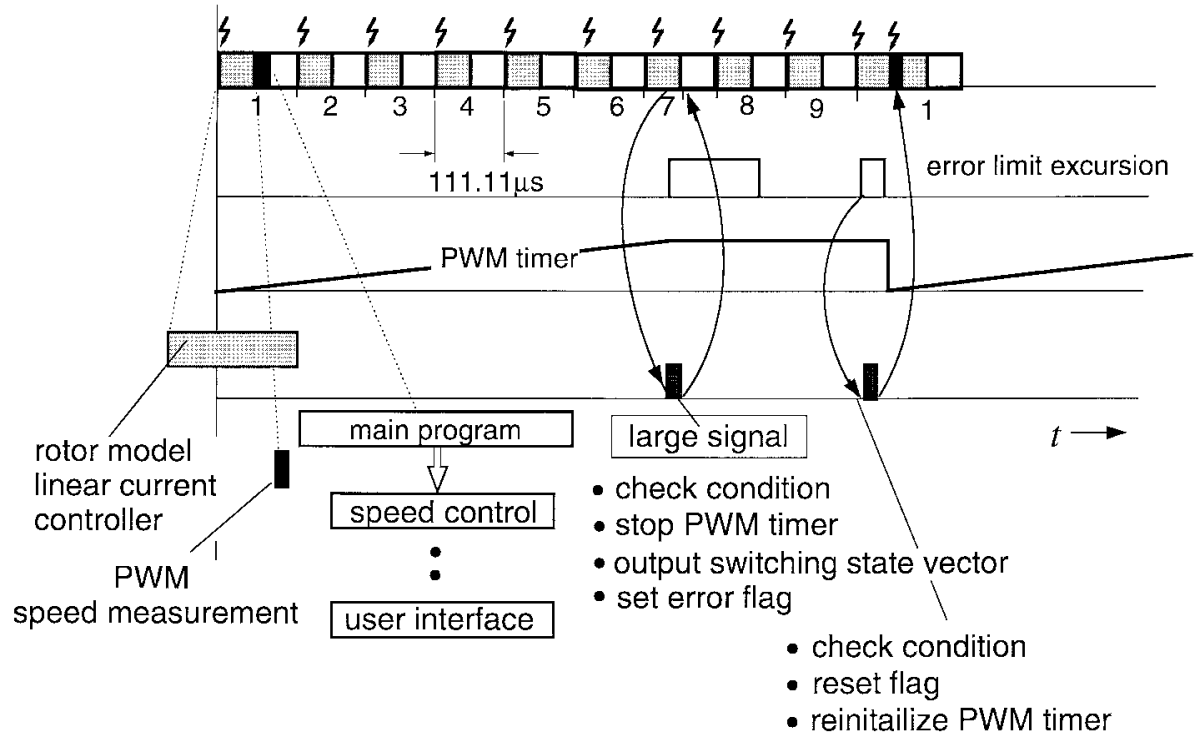

Fig. 9. Timing diagram.
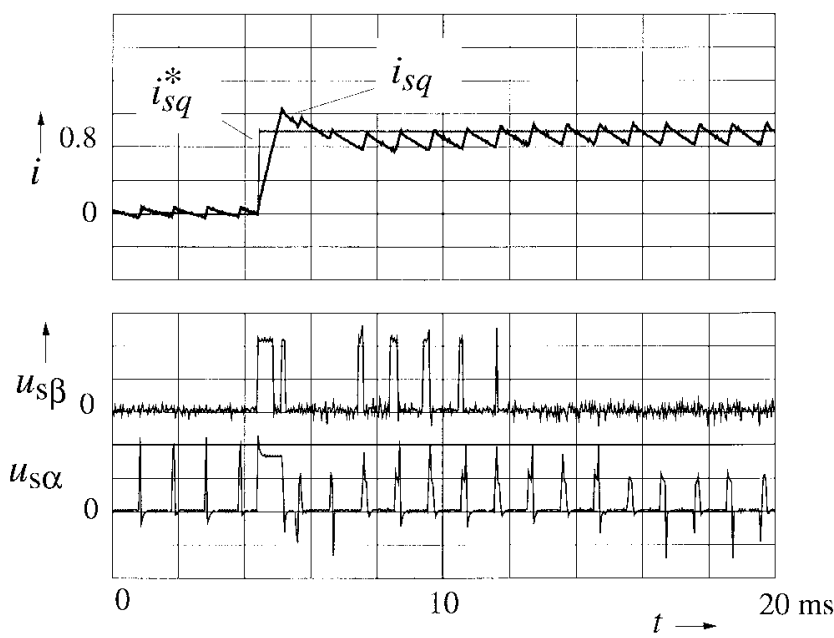

Fig. 10. Dynamic response with new scheme.

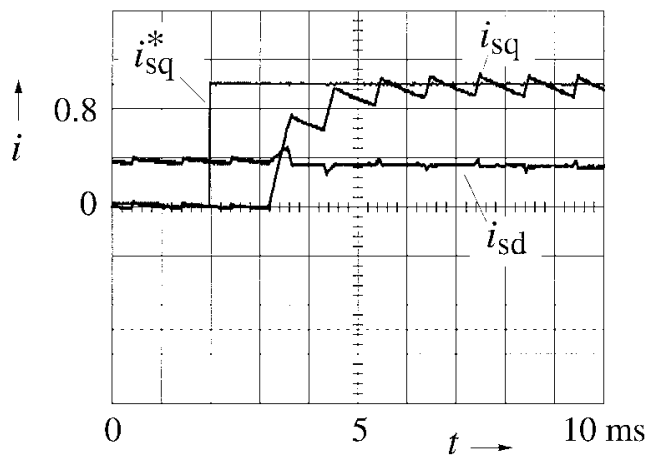

Fig. 11. Response of the linear controller.

feedforward PWM with linear controllers and feedback PWM with nonlinear controllers. The steady-state performance of the nonlinear current controllers can be improved by using
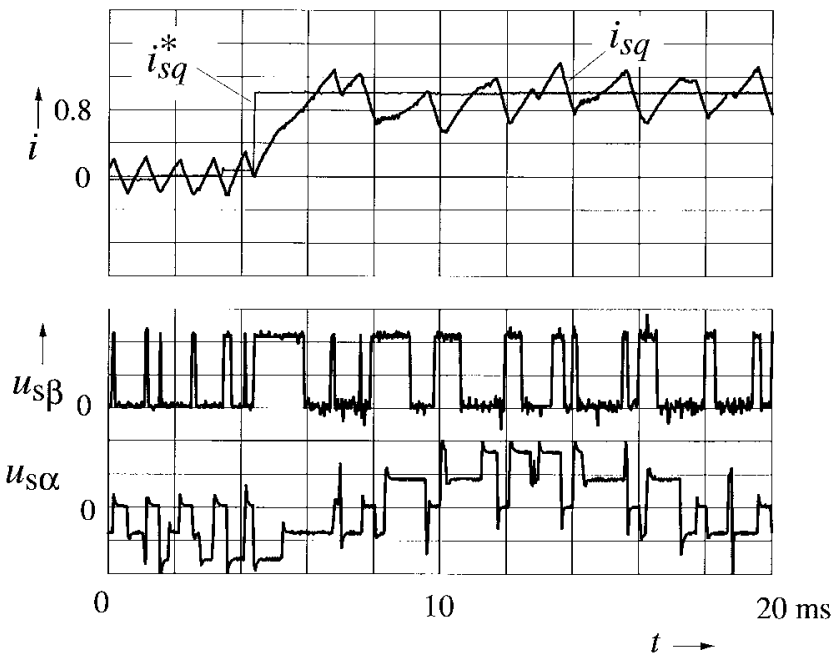

Fig. 12. Dynamic response of proposed controller at high modulation index.

on-line optimizing feedback PWM. This leads to variations in switching frequency and, hence, to underutilization of the switching capability of the inverter. The use of variablestructure current control satisfies two conflicting criteria, good steady-state performance at constant switching frequency and high dynamic performance at transients. The proposed control system is simple and can be implemented using off-the-shelf components.

\section{REFERENCES}

[1] T. Matsui, T. Okuyama, T. Takahashi, J. Sugekawa, and K. Kamiyama, "A high accuracy current component detection method for fully digital vector controlled pwm vsi-fed ac drive," in Proc. Power Electronics Specialists Conf. (PESC'88), 1988, pp. 877-884.

[2] H. R. Mayer and G. Pffaf, "Direct control of induction motor currents-Design and experimental results," in Proc. European Conf. Power Electronics and Applications, 1985, pp. 3.7-3.12.

[3] J. Holtz, "Pulsewidth modulation-A survey," IEEE Trans. Ind. Electron., vol. 38, pp. 410-420, Oct. 1992. 
[4] J. Holtz and S. Stadtfeld, "A predictive controller for the stator current vector of ac machines fed from a switched voltage source," in Proc. Int Power Electronics Conf., (IPEC-Tokyo), 1983, pp. 1665-1675.

[5] _ "Field oriented control by forced motor currents in a voltage fed inverter drive," in Proc. European Conf. Power Electronics and Application (EPE-Brussels), 1985, pp. 3.21-3.25.

[6] J. Holtz and E. Bube, "Field-oriented asynchronous pulsewidth modulation for high performance ac machines operating at low switching frequency," in Conf. Rec. IEEE-IAS Annu. Meeting, 1988, pp. 412-417.

[7] A. Khambadkone and J. Holtz, "Low switching frequency high-power inverter drive based on field-oriented pulsewidth modulation," in Proc. European Conf. Power Electronics and Applications (EPE-Florence), 1991, pp. 4.672-4.677.

[8] A. V. Anunciada and M. M. Silva, "Low switching frequency highpower inverter drive based on field-oriented pulsewidth modulation," in Conf. Rec. Power Electronics Specialists Conf. (PESC'89), 1989, pp. 683-694.

[9] L. Malesani, L. Rossetto, L. Sonaglioni, P. Tomasin, and Z. Zuccato, "Digital, adaptive hysteresis current control with clocked commutations and wide operating range," IEEE Trans. Ind. Applicat., vol. 32, pp. 316-325, Mar./Apr. 1996.

[10] H. Le-Huy and L. A. Dessaint, "An adaptive current control for pwm inverters," in Proc. Power Electronics Specialists Conf. (PESC'86), 1986, pp. 610-616.

[11] J. Holtz and A. M. Khambadkone, "Accompanying notes for tutorial on pwm in ac drives," in Proc. European Conf. Power Electronics and Applications, Brighton, U.K., 1993.

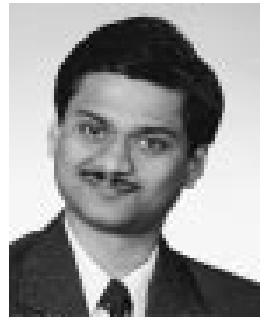

Ashwin M. Khambadkone (M'95) received the B.E. (Hons.) degree in 1985 from the University of Bombay, Bombay, India, the M.Tech degree in 1987 from the Indian Institute of Technology, Kanpur, India, and the Dr.-Ing. degree in 1995 from Wuppertal University, Wuppertal, Germany. He also holds a Graduate Certificate in Education from the University of Queensland, Brisbane, Australia.

In 1987, he joined the Electrical Machines and Drives Laboratory, Wuppertal University, as a Research Assistant. He was involved in research work in the areas of PWM methods, field-oriented control, parameter identification, and speed sensorless vector control. He was also involved in the industrial development of vector control drives. From 1995 to 1997, he was a Lecturer at the University of Queensland, where he jointly initiated research in power quality and was involved in innovative assessment and curriculum restructuring. He is currently an Assistant Profesor in the Department of Electrical Engineering, Indian Institute of Science, Bangalore, India. His research activities are in the control of high-power inverters, control of induction motor drives, and power quality.

Dr. Khambadkone was the recipient of the Outstanding Paper Award of the IEEE TRANSACTIONS ON INDUSTRIAL ELECTRONICs for the year 1991.

Joachim Holtz (M'87-SM'88-F'93), for a photograph and biography, see this issue, p. 721 . 